Canadian Journal of Family and Youth, 1(1), 2008, pp 27-62

ISSN 1718-9748 (C) University of Alberta

http://ejournals.library.ualberta.ca/index/php/cjfy

\title{
Resilience and Educational Pathways: A Longitudinal Analysis of Low Reading Achievers
}

\author{
Victor Thiessen ${ }^{1}$
}

\begin{abstract}
Utilizing the first three cycles of the Canadian longitudinal Youth in Transition Survey (YITS), this paper analyses the educational pathways of 6,342 Canadian youth who at age 15 scored below the level considered necessary for effective functioning in a knowledge-based society. The concept of resilience is integrated into a broader sociological framework of acceptance of cultural goals and access to the means for achieving these goals. Within this framework, the multiple effects of two components of resilience on educational outcomes are assessed: a) the availability of social and institutional supports and b) youth's own attitudes, values and behaviours that enabled some of them to overcome the obstacle associated with their limited reading performance. Multinomial logistic regression was used to show that a variety of possible measures of resilience differentiate between dropping out, completing high school, and participating in postsecondary education. Additionally, some aspects of resilience are more effective for avoiding the worst educational outcome (dropping out) while others appear to facilitate achieving the best outcome (participating in postsecondary education). The paper concludes that resilience is better viewed as a sensitizing than a theoretical concept.
\end{abstract}

\footnotetext{
${ }^{1}$ Victor Thiessen is a Professor Emeritus in Sociology at Dalhousie University in Canada and Professor Extraordinary at Stellenbosch University in South Africa. His recent research on youth's access and use of information and communication technology and school-work transitions have been published in academic journals such as Information, Communication and Society, Canadian Journal of Sociology, Canadian Review of Sociology and Anthropology, Journal of Youth Studies and in several edited volumes. This research was financially supported by Human Resources and Social Development Canada, and the data made available by Statistics Canada through their regional Research Data Centres. I would also like to acknowledge the constructive criticisms of the editors of the journal and two anonymous reviewers. Thiessen can be contacted at thiessen@dal.ca
} 


\section{Introduction}

The concept of resilience is often invoked to account for the puzzle that some people are able to achieve remarkable success despite considerable barriers. The popularity of the Oprah Winfrey television program is in some measure due to our fascination with the conditions under which individuals manage to "beat the odds" that life has put in their way. In the context of young people's schooling, research has consistently shown that prior academic performance is the most important predictor of subsequent educational pathways, implying that certain pathways are typical, in the sense that they are the most likely pathways: low academic performers often curtail their education, while high performers pursue postsecondary education (PSE). At the same time, the concept of educational resilience alerts us to the possibility that prior academic performance is far from deterministic. Numerous protective factors may be encountered along the way, resulting in substantial proportions of young people graduating from high school and participating in PSE despite weak earlier academic performance. For example, Entwisle, Alexander, and Olson (2004:1197) conclude that "dropouts who return possess a resilience ... that enables them to overcome their earlier academic failures."

This paper focuses on one atypical pathway, namely initial low reading achievement followed by subsequent high school completion and participation in PSE. The main obstacle considered here is below-average reading achievement at age 15, whether because of limited cognitive abilities or for other reasons. Under what circumstances and through what actions can they nevertheless obtain educational credentials that are likely to increase their human capital skills? Few studies have examined educational pathways specifically among young people whose prior academic performance (whether assessed on the basis of standardized achievement scores or marks obtained in school) was relatively poor. To date, research on educational resilience has concentrated on the effects of socio-economic disadvantage, particularly youth from low-income households (Benner and Mistry 2007; DiRago and Vaillant 2007; Entwisle, Alexander and Olson 2004; Reynolds, Ou and Topitzes 2004; Schoon, Parsons and Sacker 2004). Further, previous research fails to recognize the possibility of multiple barriers. An adequate empirical assessment of resilience needs to take into account the likelihood of multiple barriers. 
Despite its intuitive appeal, resilience has so far proven to be an elusive construct of questionable merit (Roosa 2000). As Wayman (2002:168) notes, resilience "is a multifaceted, complex phenomenon" with little consensus on its components or its measurement. Although resilience was initially conceived of as a personality trait, more recent work has discarded that approach and replaced it by a focus on social buffers and enabling mechanisms (Luthar, Cicchetti and Becker 2000). Nevertheless, resilience remains most popular in the disciplines of child developmental psychology and social work. This is unfortunate since sociologists have historically been interested in all forms of inequality of life chances (the barriers) and the responses to such inequalities (the buffers and enabling mechanisms).The aim of this paper is to recast educational resilience into a more sociological context and then to assess whether in its recast form it provides a better understanding of the educational pathways young people take when faced with the obstacle of below-average reading skills.

Merton's (1938) classic strain theory can be considered a sociological antecedent to resilience. He distinguished between cultural goals and institutional means for achieving these goals. His typology was constructed on the basis of whether individuals accepted the goals and whether they had access to the institutional means. He labeled as retreatists those who, failing to have access to the legitimate means, responded by also rejecting the goals. He describes retreatists as being "in the society but not of it" (Merton 1938:677). Resilience theorists, by not assessing an individual's goals, would simply classify such individuals as non-resilient. In Merton's approach, the truly resilient individual is the innovator. These are individuals who, although also denied access to the legitimate means, nevertheless continue to aspire to the cultural goals and manage to achieve them through innovative means. While Merton did not elaborate on what means these innovators used, resilience scholars drew attention to the role of social supports and individual enabling mechanisms. ${ }^{1}$ The important refinement to resilience suggested by Merton's typology is the crucial role of individual aspirations. By definition, cultural goals are those that are accepted by a large majority of its members, and perhaps for this

${ }^{1}$ The remainder of Merton's typology is not relevant to this paper, since it describes possible responses to those who have access to the means and therefore are not facing an obstacle. 
reason resilience scholars have typically failed to assess the aspirations of those who are facing certain barriers. This is a shortcoming, since resilience is applicable only to those who continue to aspire to a given goal.

Merton developed his typology using the example of economic success as the cultural goal and (implicitly) educational credentials as the primary means for achieving these goals. This was an appropriate example for adults. With respect to young people, however, certain modifications are necessary. During young people's school-aged years, it may be better to think of securing higher educational credentials as the immediate goal, and obtaining solid marks as the institutionally regulated means for achieving this goal.

Merton's emphasis on institutional regulation of the means, while basically warranted, needs further elaboration and refinement. If we accept that obtaining educational credentials is the primary goal of young people, then what are the institutionallyregulated means for its achievement? Fundamentally, it is the marks obtained during schooling that regulates access to educational credentials. Furthermore, the marks received should reflect solely a student's mastery of the subject matter, which in turn should reflect a combination of the student's effort and ability. So, on the teacher's side, favouritism would be negatively sanctioned, and on the student's side, any form of cheating could have severe consequences. In these ways, the means are institutionally regulated. This is a tidy conceptualization, but it is also far too simple. The underlying dynamics through which marks are assigned are considerably more complex: both parents and students attempt to negotiate marks; teachers are not immune to additional cues that may be conflated with a student's ability, such as the student's behaviour, diction, and cultural interests. These dynamics are better described as institutionally tolerated than as institutionally regulated; negative sanctions are not applied when these strategies and/or underlying dynamics are utilized, but Merton's typology ignores them.

It is Bourdieu who is particularly sensitive to these more hidden components of the means of obtaining educational credentials (Bourdieu 1986). Interestingly, both Bourdieu and Merton use the analogy of card games as a heuristic device for clarifying their approach. Card games provide a useful analogy since players are dealt hands of unequal 
value. A poor hand is one in which the cards dealt represent an obstacle to winning the game. For Merton, the game is played by mechanically following the rules of the game. In contrast, Bourdieu appreciates the importance of skill in how the game is played (Bourdieu 1990:9): "Action is not the mere carrying out of a rule, or obedience to a rule....This 'feel for the game', as we call it, is what enables an infinite number of 'moves' to be made, adapted to the infinite number of possible situations which no rule, however complex, can foresee." This "feel" for the game is part of the essential material of educational resilience.

This broader conceptualization of educational resilience has several ramifications for the empirical analysis of educational pathways. First, it is necessary to establish that educational credentials are indeed "a frame of aspirational reference" that Merton (1938:672) uses as a measure of cultural goals. Acceptance of the goals is of course a matter of degree. Second, the acceptable means are numerous and go well beyond the institutionally-regulated ones to those that are simply institutionally permitted; it is the latter in which resilience manifests itself. Third, although the main barrier considered in this paper is low reading skills, other barriers, such as household income and physical and emotional/mental disabilities, must also be held constant to properly assess the role of educational resilience. Finally, if the institutionally-permitted means can be equated with the "feel" of the game, then, as Bourdieu recognized, it will not be fruitful to try to measure resilience directly. Rather, the task is to identify the general components that might indicate greater skill in achieving the goal despite possible barriers, a task that is attempted next, together with a review of the empirical research that supports the relevance of these components.

As a first step, resilience can be conceptualized as having two main aspects: social/institutional supports and individual enabling practices. In practice the distinction between these two aspects becomes blurred, since seeking and finding social supports may itself be enabling. Nevertheless, the distinction is of some value since social/institutional supports highlight the importance of educationally-relevant social resources; the enabling practices, in contrast, focus on individual behaviours, values, and beliefs through which these assets are converted to human capital. 
Educational resilience can take the form of increased individual effort to overcome barriers. This constitutes the primary institutionally-legitimated means. Research has employed a variety of different aspects of academic effort, ranging from the amount of homework done, skipping classes or truancy, to interest in, enjoyment, and participation in classroom discussions. These have generally had independent effects on subsequent educational pathways (Bowlby and McMullen 2002; Dinovitzer, Hagan and Parker 2003; Gilbert et al. 1993; Lambert et al. 2004; Stearns, Moller and Blau 2004; Stoner-Eby 2002). In a longitudinal study, Meltzer et al. (2004) compared the processes of academic achievement among students with learning disabilities with those not having such disabilities. They found that students who perceived themselves as less competent viewed the tasks as more difficult and therefore "gave up" more easily (made less effort) and this reduced their subsequent achievement. Likewise Eccles, Vida, and Barber (2004) found that academic achievement was related to parental rating of their child's perseverance in the face of difficulties, which the authors considered to be a form of resilience.

A second form of resilience is avoidance of risky behaviours. In a longitudinal study Sussman, Rohrbach, Skara, and Dent (2004) found that youth in alternative high schools who reported that they intended not to use soft drugs during the next year were more likely to have graduated from high school five years later. From a life course perspective, early initiation of sexual activity is a risk factor with respect to educational trajectories. Bowlby and McMullin (2002) found that youth who had become parents were more likely to drop out of high school, as did those who formed marital-type relationships. Early parenthood may be more deleterious for girls than for boys; among females, those who expressed the intention to postpone parenthood until after the age of 24 had higher educational attainments than those who intended to have children earlier, whereas among males there was no association (Scott 2004). Krahn (2006) documented that early transitions to marriage reduced the likelihood of earning any PSE credential.

Involvement in adult-supervised activities appears to facilitate positive educational outcomes (Jordan and Nettles 2000). For example, extracurricular participation, both inside and outside of school, is positively associated with educational pathways (Aschaffenburg and Maas 1997; Butlin 1999; Mahoney 2000; Videon 2002), effects that 
persist but with diminished magnitude after controls for selection effects, such as parental education, are introduced. Likewise, doing volunteer work is found to be associated with various educational outcomes, including marks and educational attainment. However, these effects diminish substantially after including controls on parental education and social status (Eccles and Barber 1999).

Being employed during high school can be considered an additional form of time spent under adult supervision. At the same time, intensive employment during the school year can be risky with respect to future educational outcomes. The empirical literature is consistent with both points of view, since those not working at all as well as those employed for more than 20 hours per week being more likely to drop out than those who worked a moderate amount (Bowlby and McMullen 2002; Tomkowicz and Bushnik 2003). An important additional finding is that those who worked during the school year prior to dropping out were more than twice as likely to return as those who did not work (Entwisle, Alexander and Olson 2004). This suggests that the labour market did not "pull" students out of school. Rather, it suggests that paid employment develops educational resilience, either through increased motivation and self-discipline, or through the positive effects of spending structured time in adult-supervised activities.

In the context of formal education, Bourdieu sensitizes us to the crucial role of parents (1977; 1978). Parents have a vested interest in their children's educational success. The linked lives of parents and children must be incorporated into any analyses of young people's educational resilience. It is the aspirations and expectations parents hold for their children's education that appear to be pivotal, with a recent review of the literature finding them to be the most salient form of parental influence (Fan and Chen 2001). While parental expectations are tempered by reality constraints, they consistently show strong independent associations with educational pathways after controlling for marks and parental socio-economic status (Crosnoe, Mistry and Elder 2002; Tomkowicz and Bushnik 2003).

Social supports of peers and teachers have generally also been associated with better educational outcomes. Zaff (2003) found that students who reported that at least one 
friend dropped out were less likely to pursue PSE. Likewise Tomkowicz (2003) reported that the likelihood of immediate participation in PSE steadily increased with the number of friends planning to participate in PSE. Having friends who took school seriously was related to high attainment, and more young women than young men had peer groups that took school seriously (Tinklin and Croxford 2000); the latter finding might be one of the reasons females generally have both more resilience and better educational outcomes than males (Eccles, Vida and Barber 2004; Wasonga 2002). In a longitudinal study of middle school children, Bouchey and Harter (2005:680) documented that support from both parents and teachers was important for subsequent academic performance and that "perceived support from teachers had a direct effect on math/science performance." Likewise Hymel and Ford (2003) found that even after controlling for cognitive ability, later school performance was linked to the early influences of teachers as well as parents. Yet Crosnoe et al. (2004) found only a modest relationship of teacher support with academic achievement. At the same time, Wood, Kaplan and McLoyd(2007) found that teachers could buffer the negative effects of low parental educational expectations. Benner and Mistry(2007) come to the same conclusion. Finally, Schoon, Parsons, and Sacker (2004) found that parental educational aspirations, were significantly more important in socio-economically disadvantaged than in advantaged homes.

In addition to social supports, the economic, social and cultural capital parents possess are known to have relatively strong effects on all markers of educational attainment, such as dropping out (Bowlby and McMullen 2002; Crowder and Teachman 2004; Dinovitzer, Hagan and Parker 2003; Pong and Ju 2000; Stearns, Moller and Blau 2004; Stoner-Eby 2002; Teachman, Paasch and Carver 1997) and pursuing postsecondary education (Butlin 1999; Cheung and Andersen 2003; Crosnoe, Mistry and Elder 2002; Lambert et al. 2004; Zaff et al. 2003). The important issue concerns the underlying processes through which household advantages are converted to improved educational outcomes. Looker (1994) argues that parental capital must be activated. Such activation takes a variety of possible forms, such as better monitoring of their children's activities or equipping the home with computers and other educationally-relevant resources. In this respect, there is some 
evidence that children with home access to computers perform better in school (Attewell and Battle 1999).

Other characteristics of the household, such as family structure and immigration status can also be viewed from the point of view of buffers and constraints. Coleman's (1988) seminal work on parental social capital has spawned much research on the effect of single parenthood on their children's educational outcomes. These showed that living with two biological parents increased the odds of completing high school even after controlling for household income and parental education (Evans, Kelley and Wanner 2001; Musick and Bumpass 1999; Pong and Ju 2000). In a similar vein, residential mobility interferes with solid educational outcomes (Glick and White 2004; Hagan, MacMillan and Wheaton 1996; Pribesh and Downey 1999) presumably because it reduces the previouslydeveloped network of social supports.

While the empirical literature documents the relevance of resilience to educational outcomes, it also shows that ultimately how well one performs in class is paramount: all aspects of academic performance are crucial for understanding subsequent educational transitions (Butlin 2000; French and Conrad 2001; Glick and White 2004; Lambert et al. 2004; Stearns, Moller and Blau 2004; Stoner-Eby 2002; Tomkowicz and Bushnik 2003; Zaff et al. 2003). As noted previously, marks constitute the main institutionally-regulated means for obtaining educational credentials. Yet many young people with sufficiently high marks to complete high school and to enroll in postsecondary education don't. This raises the question of whether resilience operates simply to improve academic performance, or whether it has additional direct beneficial effects that keeps young people from dropping out and encourages them to pursue postsecondary education.

\section{Method}

\section{Data}

The analyses are based on an extension of the Canadian portion of the Program for International Student Assessment (PISA) reading achievement survey of 15-year-olds conducted in 2000. A two-stage sampling design was used, with the first stage being 
schools and the second stage being students within schools. Schools located on First Nations reserves and in the northern territories were excluded from the sampling design. ${ }^{1}$ The Canadian portion was augmented in two ways: First, an additional questionnaire was administered to the student, as well as an interview with their parent/guardian, usually the mother. Second, two follow-up telephone interviews were conducted with the youth in 2002 and 2004. The augmented data are known as the Youth in Transition Survey (YITS). The response rate for the baseline survey was 86.6 percent; the response rates for the two follow-up surveys were 90.5 percent and 84.3 percent (see Statistics Canada 2006 for further information on sampling and measurement issues). For each cycle, Statistics Canada recalibrated a set of respondent weights that takes non-response among other factors into account, making it possible to provide parameter estimates that are representative of the original population of 15-year olds. Cycle 3 weights are employed throughout. Analyses are restricted to the 6,342 youth who scored below Level 3 on the reading achievement test administered during the first cycle in 2000 and who provided information on educational pathway at age 19. Students whose reading achievement score fell below Level 3 typically cannot "integrate several parts of a text" nor "understand a relationship or construe the meaning of a word or phrase" (Human Resources Development Canada, Council of Ministers of Education and Statistics Canada 2001:24). Difficulties with tasks such as these arguably constitute significant obstacles to future educational outcomes.

\section{Measure of educational pathway}

The outcome variable is the educational pathway of these young people at age 19. At this age, educational pathways are particularly fluid: some who have dropped out of school will complete their high school at a future point in time; others are still in high school

\footnotetext{
${ }^{1}$ It is well-known that the educational pathways of young people living on First Nations reserves and in Canada's northern territories are decidedly less favourable than those of other Canadian population groups (Thiessen, 2007). Hence the analyses presented in this paper can be generalized only to youth living in the 10 provinces and not living on a First Nations reserve. Statistics Canada concluded that the number of cases of First Nations youth living off-reserve was too small to warrant identifying them in the data set.
} 
despite being 19 years old because they have experienced grade retention. The analysis presented here is incomplete since it represents a snapshot at a particular point in time. Additionally, in order to retain sufficiently large numbers of cases to make stable estimates, it is necessary to collapse certain pathways. For the purposes at hand, three groups are of particular interest: dropouts, high school graduates who did not pursue PSE, and those who participated in PSE. The definitions of these groups and their distribution are as follows:

High school dropouts (26.9\%) did not complete the requirements for a high school graduation certificate or its equivalent by the age of 19. It excludes students who participated directly in a PSE program without graduating from high school. Included, however, are those who are currently enrolled in high school. Given their age, they represent those whose high school completion has been delayed for reasons such as grade retention, prior dropping out and returning, or disabilities that have delayed the normal progression through the school system. One could argue that those still in high school exhibit unusual resilience in that they have refused to give up the pursuit of educational credentials despite impeded progress and that therefore they should either be eliminated or combined with high school graduates. The analyses were replicated using these alternative definitions. The main findings are consistent regardless of which definition is used, although minor refinements will be pointed out at the relevant points. In any event, exploratory analysis indicated that in most respects, they are similar to dropouts and for this reason they are combined with the dropouts in all tables.

High school graduates (37.5\%) obtained a high school completion certificate or its equivalent by the age of 19 but have not participated in any PSE program.

PSE participants $(35.6 \%)$ are currently or were previously enrolled in, or completed, a PSE program.

\section{Measures of independent and control variables}

The YITS data is rich in information on educational aspirations, possible barriers to educational attainment, parental resources, and possible measures of resilience in the 
form of social supports and individual behaviours. Additionally, it contains sociodemographic information on factors known to be determinants of educational pathways. The information below provides the operational definitions of the variables employed; dichotomous indicator variables are labeled to represent the category of inclusion.

Educational aspirations: Response options to the question "What is the highest level of education you would like to get?" ranged from "less than a high school diploma" to "PhD". The responses were recoded to represent the approximate number of years of education.

Reading and math achievement: These are PISA-developed item-response theory measures calibrated so that the international mean is 500 with a standard deviation of 100.

Health barrier (indicator): The parent/guardian was asked "Does a physical condition or mental condition or health problem reduce the amount or the kind of activity your child can do at school?"

Parental income: The parent/guardian was asked detailed questions about their own and spouse's (if applicable) earned income and other sources of income. Statistics Canada combined these into a measure of total income. To avoid skew and outliers, total income was transformed into quintiles.

Parental education: The parent/guardian was asked about their highest level of education and that of their spouse (if applicable). These were converted to the approximate number of years of education and then the mean was calculated. Youth's report of their parents' education was substituted whenever the parent's report was not ascertained.

Availability of home computers: Respondents were asked whether there was a computer available for their use at home and whether it was connected to the internet. Responses were combined such that $0=$ no home computer; $1=$ home computer but no internet; 2 = home computer with internet. 
Parental educational support: Responses to whether the youth believed it was "very important" to their parents that they a) complete high school and b) pursue PSE were combined such that $0=$ neither was very important; $1=$ one was very important; 2 $=$ both were very important.

Parental confidence: After responding to the question "What is the highest level of education that you hope your child will get?" the parent/guardian was asked: "How certain are you that your child will get that far?" The four Likert-type response options ranging from "very certain" to "very uncertain" were reversed so that a high score equals parental confidence.

Teacher support: The mean of seven Likert-type items such as "There were teachers or other adults in my school whom I could talk to if I had a problem."

Peers' educational plans and values: The youth were asked to "think about your closest friends during your last year of high school." How many of these friends thought completing high school was very important" and additionally "how many of them "planned to further their education or training after leaving high school." Response options were $1=$ none, $2=$ some, $3=$ most, and $4=$ all of them. The index consists of the mean of the two items.

Changed high schools (indicator): Statistics Canada derived this variable from information about the high schools the youth had attended.

Academic effort: A PISA-supplied item-response theory scale comprised of items such as the amount of time spent on homework.

Homework hours: Youth were asked "During your last year about how many hours each week did you spend on homework outside class, during free periods and at home?" The six response options ranged from zero hours to 15 hours or more. These were recoded to represent approximate number of hours per week. 
Victor Thiessen

Frequency of class absences: Youth were asked "How often did you cut or skip classes without permission?" Response options ranged from "never" to "more than once a week." These were recoded into an approximate count of the number of absences in a 10month school year.

GPA: Youth's response to "In your last year of high school, what was your overall grade average, as a percentage?"

University-preparatory classes: The youth were asked at what level they had taken their last math and language arts classes. The responses were combined such that 0 $=$ neither the last math nor language class was taken at a university-preparatory level; $1=$ either math or language; and 2 = both.

Parent (indicator): Youth were asked: "Do you have any dependent children? Include birth, adopted, stepchildren and foster children."

Alcohol/marijuana use: After a reminder that their answers would remain confidential, youth were asked how many times per month during their last year at high school they had consumed alcoholic beverages and how many times they had used marijuana or hash. Response options ranged from "never" to "more than once a week." The index consists of the mean of the two responses.

Paid employment (indicator): This indicator variable was constructed from the responses to"During the school year, about how many hours each week did you work at a job for pay? Also count odd jobs for pay, but not work placements for school like Co-op or other work education programs." A score of 1 indicates that they worked at least one hour per week.

Extracurricular participation: Youth were asked whether in their last year of high school they had participated in "any school clubs, teams, or other school organization." Additionally there were asked whether they had participated in "non- 
school clubs, teams, volunteer work or other organizations-for example community sports, music lessons or youth groups not organized through school." Responses to the two questions were combined such that $0=$ participated in neither; $1=$ participated in 1; and 2 = participated in both).

Initiative: Youth were asked whether on their own initiative during the past year they had done any of the following six things to "learn or acquire skills for a job or career": used the internet; read books, manuals or other written materials; used a computer assisted teaching software; used videos, cassettes, CDs, television, radio or DVDs; watched others work or received advice or assistance from others; participated in any other learning activities. The index consists of a count of the number of things they had done.

Perseverance: The five Likert-type response options to the item "When school work was very difficult, I stopped trying" were reversed so that $5=$ "never"; $1=$ "always".

Participation in career preparation activities: The number out of 10 schoolprovided activities that the youth had participated in (write a resumé, how to search for a job, prepare for a job interview, learn about jobs, meet with a school counselor, complete a questionnaire to find out about your interests or abilities, visit an internet site or use a computer program to help you decide what college or university program or courses to take, obtain information on student financing, go on an organized campus tour, attend a presentation by people working in different types of jobs).

Female (indicator): "Are you female or male?"

Visible minority (indicator): Information was supplied by the parent/guardian. Statistics Canada derived this variable and defines it as "persons who are identified according to the Employment Equity Act as being non-Caucasian in race or non-white in colour. Under the Act Aboriginal persons are not considered to be members of visible minority groups." 
Immigrant (indicator): The parent/guardian was asked whether the child had ever been a landed immigrant to Canada. The youth was also asked this question, and the youth's response was substituted if the information was not ascertained in the parent questionnaire.

Two biological parents (indicator): The parent/guardian was asked about their own and their spouse's (if applicable) relationship to the child. Statistics Canada derived a variable that indicated whether both birth parents lived in the household. Where information from the parent questionnaire was not available, the child's report was substituted.

\section{Hypotheses}

Three hypotheses guide the analyses:

- Resilience among low reading achievers decreases the likelihood of dropping out of high school and increases the odds of pursuing PSE. Both aspects of resilience (individual enabling mechanisms and social supports) are expected to contribute to better educational outcomes. At the same time, in the face of low reading literacy, some young people will respond by relinquishing the cultural value of higher education.

- Both aspects of resilience are expected to have direct effects that are neither mediated through academic performance nor reflect socio-economic selection effects. That is, manifestations of resilience are expected to be statistically significant and substantively important after controlling for other barriers and resources, socio-demographic factors, and academic performance (the institutionally-regulated means of obtaining educational credentials).

- Resilience is expected to have beneficial effects for both completing high school and for participation in PSE. Since there are no compelling theoretical reasons, nor relevant empirical studies to expect resilience to be more important for the one educational outcome than the other, it is hypothesized that resilience will play an approximately equal role for the two outcomes. 
This study contributes to previous resilience research in five ways. First, it focuses on a form of adversity that has not received much attention, namely youth with poor reading skills. Can the resilience framework be fruitfully generalized to the barrier of low reading skills? Second, it is based on a large, nationally-representative Canadian survey. Many resilience studies were conducted on relatively small and/or nonrepresentative samples from the USA. Third, the data is longitudinal, with barriers/resources and socio-demographic factors measured at age 15, while resilience was measured at age 17, and the outcome at age 19. This helps address the vexing issue of causality versus selection effects. Fourth, using multinomial logistic regression, this paper permits one to address whether resilience is more important for avoiding poor educational outcomes (dropping out of high school) or for attaining particularly good ones (pursuing post-secondary education). Finally, it assesses a more sociologicallyinformed conceptualization of resilience by incorporating consideration of the rejection of cultural goals and of multiple barriers to the means of achieving these goals.

\section{Results}

\section{Bivariate profiles of educational pathways}

At a descriptive level, all measures of barriers and resources that were available at age 15 , as well as all measures of social supports and possible aspects of resilient behaviours (at age 17), are statistically significantly associated with educational pathways (at age 19), albeit some have rather weak bivariate associations as shown by the low proportion of explained variance (see $\eta^{2}$ of Table 1). The final column of this table provides the percentage of missing cases for each of the variables. ${ }^{1}$ A closer examination of this table reveals a number of consistent patterns. The first row documents that obtaining educational credentials is a pervasive cultural value that is accepted by virtually all young people. Regardless of their educational pathway, young people aspire to substantially more education than they currently have. Nevertheless, there are also clear signs that some young people are beginning to reject this value. This is inferred from the fact that

\footnotetext{
${ }^{1}$ The high percentage of missing values for math achievement is due to the fact that the math achievement test was administered to only a sub-sample of the students.
} 
Victor Thiessen

dropouts have the lowest educational aspirations (on average about two years of PSE) while those participating in PSE have the highest (almost four years of PSE). 
Table 1: Profile of educational pathways

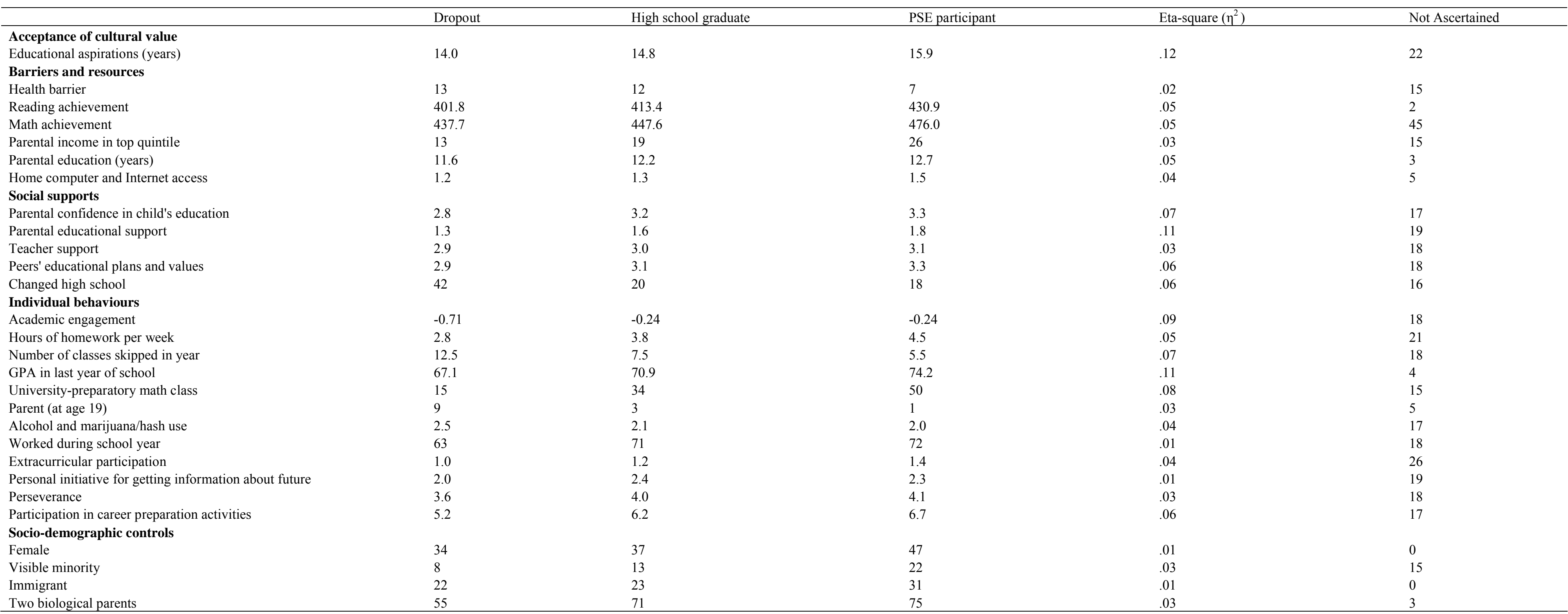

Two biological parents

Note: In the first three columns, whole numbers are percentages for the indicator variables; all other numbers are means for indices. 
The next six rows show that obstacles and resources are patterned in a consistent way: Dropouts faced the greatest barriers, while those who participated in PSE enjoyed the greatest access to resources and least severe barriers. Note that even though all young people analyzed here have below-average reading skills, these skills are still unequally distributed, with dropouts having the lowest reading literacy while those who pursued PSE had obtained the highest reading achievement scores.

The first component of educational resilience - the availability of social supportsoperates as expected: the greater the social supports from parents, teachers, and peers, the better the educational pathway. Note that changing high schools might be an indirect measure of the loss of teacher and/or peer supports.

The second component - individual enabling behaviours — shows the same pattern. Least surprising is that the institutionally-regulated means (GPA) to credentials is strongly related to educational pathways. It is therefore also to be expected that behaviours that improve marks (academic effort in the form of doing homework and regular class attendance) show the same pattern. Spending time in adult-supervised activities, whether in paid employment or in extracurricular activities, differentiates between the educational pathways, with dropouts being least likely and PSE participants most likely to have spent time in these activities. Likewise, avoiding risky behaviours such as unprotected sexual activity appears to have beneficial consequences for subsequent educational pathways.

Exhibiting initiative might be considered a particularly clear form of resilience. In light of this, it is surprising that it is only weakly associated with educational pathways at the bivariate level. A second type of enabling behaviour, persistence in the face of difficulties, shows a stronger relationship, as does participation in career preparation activities.

Finally, females, visible minorities, immigrants, and youth living with both biological parents $^{1}$ are least likely to drop out and most likely to participate in PSE.

For some measures of educational resilience, identical questions were asked in the first two cycles. Since resilience is better conceptualized as a process than a state (Luthar, Cicchetti and Becker 2000), one should see manifestations of resilience over time. Table 2 shows the relationships of three aspects of effort (at ages 15 and 17, and the changes that occurred between these two ages) on educational outcomes: persevering when school work is difficult, attending classes and doing homework.

\footnotetext{
${ }^{1}$ The decision to collapse the many possible forms of family structure into a dichotomy was based on two considerations. First, previous research has shown that living with both biological parents is consistently associated with better academic and educational outcomes than is either living with two parents who are not biological or living in a single-parent household. Second, although there are some differences between singleparent and step-parent households, the number of cases for some of these other family structures is too small to provide stable estimates of their effects.
} 
Table 2: School work effort by age and educational pathway (\%)

\begin{tabular}{|c|c|c|c|}
\hline & Dropout & Graduate & PSE \\
\hline \multicolumn{4}{|c|}{$\begin{array}{l}\text { A) Skipped classes at least } \\
\text { once a month }\end{array}$} \\
\hline Age $15 * * *$ & 44 & 33 & 26 \\
\hline Age $17 * * *$ & 60 & 45 & 33 \\
\hline Change*** & 16 & 12 & 7 \\
\hline \multicolumn{4}{|c|}{$\begin{array}{l}\text { B) Four or more hours } \\
\text { homework per week }\end{array}$} \\
\hline Age $15 * * *$ & 13 & 22 & 31 \\
\hline Age $17 * * *$ & 31 & 44 & 57 \\
\hline Change*** & 18 & 22 & 26 \\
\hline \multicolumn{4}{|c|}{$\begin{array}{l}\text { C) Never stopped trying } \\
\text { when school work was } \\
\text { difficult }\end{array}$} \\
\hline Age $15 * *$ & 16 & 16 & 19 \\
\hline Age $17 * * *$ & 38 & 49 & 53 \\
\hline Change*** & 22 & 33 & 34 \\
\hline \multicolumn{4}{|c|}{ D) Obtained GPA of B or better } \\
\hline Age $15 * * *$ & 44 & 58 & 68 \\
\hline Age $17 * * *$ & 39 & 57 & 75 \\
\hline Change*** & -5 & 1 & 8 \\
\hline
\end{tabular}


Panel A documents that at both age 15 and 17, low reading achievers who had better educational pathways at age 19 attended classes more regularly. Although skipping classes became more frequent over their high school careers, the better the educational pathway, the less likely it was that students would skip classes more frequently. This can be seen by comparing the age 15 and age 17 percentages for each group. Among those who ultimately dropped out, 16 percent fewer $(60-44=16)$ attended classes regularly at age 17; in contrast, among PSE students, this decline amounted to only 7 percentage points. Similarly, at both points in time, the more homework done, the better the educational outcome (Panel B). Furthermore, as was found for class attendance, youth on better educational trajectories became even more likely over time to increase the amount of effort they put into homework than did those who dropped out. Among dropouts, only 18 percent more put in at least four hours of homework per week, compared to 26 percent among postsecondary students. Panel $\mathrm{C}$ shows that at age 15, low reading achievers differed little in their self-reported perseverance when school work was difficult, with only three percentage points separating those who had dropped out by age 19 from those who pursued post-secondary education. Two years later, the differences in academic perseverance were substantial: Only 38 percent of dropouts never stopped trying when school work was difficult, compared to 53 percent of those who participated in postsecondary education.

Since educational pathways are strongly influenced by academic performance, it should be the case that such performance increases among those with better outcomes. As expected, at both age 15 and 17, the likelihood of having obtained a GPA of B was higher the better the educational trajectory (Panel D). Note, however, that among those who pursued PSE, the likelihood of obtaining a solid GPA increased between age 15 and 17, whereas among dropouts it decreased.

\section{Multivariate Analyses}

The profile analysis suggested that five types of factors that are relevant to resilience research may be implicated in educational pathways: acceptance of the value of educational credentials, barriers and resources, resilience in the form of social supports, 
resilience as manifested in various types of enabling behaviours, and socio-demographic factors. The profile analysis also showed that both the acceptance of the cultural goals and access to resources (and/or the absence of obstacles) were related to educational pathways in the same manner as all measures of resilience. This raises the possibility that resilience per se has no causal connection to educational pathways: their apparent bivariate relationship with educational pathways may be an artifact of their access to resources and absence of barriers additional to those of their low reading skills. To assess this causality issue requires multivariate analysis.

Because of the nested sampling design and the categorical nature of the outcome variable, hierarchical multinomial logistic regression models are employed to contrast three educational pathways: 1) High school dropouts, 2) high school graduates with no further PSE, and 3) participants in PSE. Missing values plague all multivariate analyses, and youth with low reading achievement have particularly high non-response rates (see the last column of Table 1). To retain a representative sample, means were substituted for missing values and indicator variables for missing values were constructed. Several different ways of measuring the effect of missing values were introduced as control variables. None of them proved to be statistically significant, leading to the conclusion that mean substitution did not bias the findings significantly. Hence the multivariate analyses do not include missing value indicators.

To address the causality issue, two multinomial models are constructed. The first model, which for simplicity is labeled the resource model, introduces two types of variables: barriers and resources that were available when the youth was 15 years old; and sociodemographic controls for variables known to be associated with educational pathways (also measured at the baseline survey). Model 2, labeled the resilience model, adds acceptance of the cultural value of education (measured as educational aspirations) as well as the possible measures of resilience in both the form of social supports and enabling behaviours. With the exception of parenthood, these were measured during the second cycle when the respondent was 17 years old. There were too few instances of parenthood at age 17 to permit including this measure of risk at that age; yet this marker of early transition to adulthood is an important one and therefore it is included from the 
Victor Thiessen

third cycle of information. The resilience model excludes those aspects of resilience that failed to be statistically significantly related to educational pathways even in the absence of the controls introduced in the first model. These are: personal initiative, academic perseverance, intensive employment, and teacher supports.

Table 3 provides the odds ratios contrasting high school graduates with dropouts (columns 1 and 2), as well as for postsecondary participants versus high school graduates (columns 3 and 4). 
Table 3: Odds ratios for multinomial models of educational pathways

\begin{tabular}{|c|c|c|c|c|}
\hline & Graduate versus Dropout & & PSE versu & \\
\hline & Resource & Resilience & Resource & Resilience \\
\hline Intercept & $1.31 *$ & $1.66 * * *$ & $0.57 * * *$ & $0.56 * * *$ \\
\hline Female & $1.33 *$ & 1.18 & $1.57 * * *$ & $1.33 * *$ \\
\hline Visible minority & $2.02 * * *$ & 1.46 & $1.82 * * *$ & $1.42 *$ \\
\hline Immigrant & 0.82 & $0.70^{*}$ & $1.33 *$ & $1.33^{*}$ \\
\hline Two biological parents & $1.76 * * *$ & $1.62 * * *$ & 1.10 & 1.05 \\
\hline Health barrier & 0.82 & 0.93 & $0.74 * * *$ & 0.80 \\
\hline Parental education & $1.30 * * *$ & $1.22 * *$ & $1.31 * * *$ & $1.26 * * *$ \\
\hline Income (in quintiles) & 1.04 & 1.04 & $1.08 *$ & 1.08 \\
\hline Changed high school & $0.43 * * *$ & $0.47 * * *$ & 0.84 & 0.83 \\
\hline Home computers and Internet & 1.08 & 1.03 & $1.19 * * *$ & $1.16^{* *}$ \\
\hline Reading achievement & $1.15^{* *}$ & 1.07 & $1.36 * * *$ & $1.28 * * *$ \\
\hline Math achievement & 1.08 & 1.03 & $1.31 * * *$ & $1.27 * * *$ \\
\hline Educational aspirations & & 1.07 & & $1.28 * * *$ \\
\hline GPA & & $1.35 * * *$ & & $1.31 * * *$ \\
\hline University-preparatory classes & & $1.49 * * *$ & & 1.03 \\
\hline Frequency of class absences & & $0.78 * * *$ & & $0.89^{*}$ \\
\hline Academic effort & & $1.18^{*}$ & & $1.15^{*}$ \\
\hline Importance of education to parents & & $1.23 * * *$ & & $1.24 * * *$ \\
\hline Parental confidence & & $1.35^{* * *}$ & & 1.06 \\
\hline Peer educational support & & 0.98 & & $1.19^{* *}$ \\
\hline Paid employment & & $1.55^{* * *}$ & & 0.93 \\
\hline Parenthood & & $0.32 * * *$ & & $0.47 *$ \\
\hline High school job/education preparation & & $1.24 * * *$ & & $1.16^{* *}$ \\
\hline Alcohol/marijuana use & & 0.90 & & 1.10 \\
\hline Nagelkerke Pseudo $\mathrm{R}^{2}$ & 0.23 & 0.41 & 0.23 & 0.41 \\
\hline
\end{tabular}


To make the parameter estimates comparable, continuous measures were converted to standard scores. Indicator variables are named for the category of inclusion (for example, gender is named "female" to indicate that males $=0$ and females $=1$ ). Several examples should help clarify how to read the odds ratios. Focusing on the first column, it can be seen that the odds of females graduating rather than dropping out are 1.33. This means that females have 33 percent higher odds than males of completing high school rather than drop out (an odds ratio of 1.0 would indicate equal odds, or no gender difference). Similarly, the odds of visible minorities completing high school rather than dropping out are about twice those of their white counterparts. In contrast, youth who changed high schools have 57 percent $(1-0.43=.57)$ lower odds of graduating than those who obtained all of their high school education at the same school. In short, for all dichotomous indicator variables, the odds ratios indicate the effect of membership in a given category. For continuous variables, the odds ratios estimate the effect of a one standard deviation increase in the given independent variable on the educational pathways that are being contrasted. For example, a one standard deviation increase in reading achievement increases the odds of completing high school by 15 percent.

The resource models (columns 1 and 3) show that all forms of resources and barriers, as well as all of the socio-demographic controls are significantly related to one or the other or both educational pathway contrasts. Females, visible minorities, children whose parents have more education, and those with higher reading skills are more likely to complete high school rather than to drop out as well as being more likely to pursue PSE rather than to curtail their education with a high school completion certificate. Youth who changed high schools are significantly less likely to complete high school, but there is no significant effect on their likelihood of pursuing PSE. In contrast, youth with better math skills, coming from higher income homes, and having home access to information and communication technology (ICT) are significantly more likely to participate in PSE, but these same factors have no appreciable effect on their likelihood of completing high school. Likewise, having a disability represents a barrier to pursuing PSE but not to 
completing high school. The resource model accounts for 23 percent of the variation in educational pathways.

The resilience model accounts for an additional 18 percent of the variation in educational pathways, indicating that collectively the measures of resilience have substantial effects additional to those of the resource model. The parameter estimates for the resilience models reveal that, with the exception of alcohol and marijuana use, ${ }^{1}$ all aspects of resilience have additional effects independent of those considered in the resource model on either completing high school or pursuing PSE or both. The institutionally regulated means for obtaining educational credentials (namely marks, academic effort, and regular class attendance) are associated with both high school graduation and PSE participation in the expected direction. Likewise, participation in high school job/education preparation activities facilitates both high school completion and PSE participation. When youth believe that their educational attainment is important to their parents, they are more likely both to complete high school and to pursue PSE. Early transition to parenthood has negative effects on both pathways, while parental confidence in their child's likelihood of attaining their educational aspirations appears to be an especially important buffer keeping their child from dropping out. Somewhat surprisingly, neither educational aspirations nor having peers that value education appear to be factors in young people's decision to drop out, although both are associated with the decision to pursue PSE in the expected direction.

\section{Conclusions}

This paper examined factors that might account for solid educational trajectories among Canadian youth who faced the barrier of prior below-average reading achievements. Perhaps the most important finding is that many aspects of youth's resilience operated to

\footnotetext{
${ }^{1}$ If students still in high school at age 19 are excluded from the category of dropouts, then alcohol and marijuana use is significantly related to high school graduation. Specifically, alcohol or marijuana use decreases the odds of completing high school by more than a quarter $(27 \%)$, a finding that suggests that youth who refuse to dropout despite having experienced educational setbacks in the form of one or more grade retentions are perhaps especially resilient.
} 
improve their educational outcomes. A variety of individual enabling mechanisms and social supports appear to have beneficial effects on subsequent educational pathways. By not engaging in risky behaviours (early unprotected sexual activity, consuming alcohol and/or marijuana, having intensive paid employment), by maintaining high educational goals, by taking advantage of school-provided activities and a variety of social supports, low reading achievers were often able to overcome the obstacle presented by their reading performance. Collectively, these findings support the first hypothesis.

Is resilience simply a byproduct of various socioeconomic advantages that accrue from such factors as growing up with both biological parents who are well-educated or affluent and who equip the home with computer technology? Or is resilience in its varied forms assessed here able to provide young people of below-average reading achievement the personal resources that enable them to achieve better than expected educational outcomes even after controlling for any home advantages? The findings show quite unequivocally that resilience as measured here represents enabling factors that operate in addition to the socio-demographic factors that previous research has documented to be consistently, and strongly, related to educational attainment. This supports the conclusion that young people with limited reading achievement can initiate a series of behaviours between the ages of 15 and 17 that enable them to complete high school and even pursue postsecondary education. Further, such resilience is not merely an artifact of selection factors associated with prior home advantages. In short, the second hypothesis is supported in that educational resilience has both direct and indirect effects on educational outcomes.

Some important differences emerged between specific educational transitions. One such difference is that the process of dropping out seems not to be primarily a matter of either ability or poverty, since neither math achievement scores nor household income (or its activation in equipping the home with computers) differentiates between dropouts and high school graduates. In contrast, all of these variables are significantly related to pursuing PSE. A second difference concerns family structure. Living with both biological parents appears to be an important buffer against dropping out; the odds of completing high school are estimated to be 76 percent higher when youth live with both biological 
parents. Previous literature has debated whether other types of family structures are "deficient" with respect to their social capital, or whether the family structure effect is an artifact of lower parental economic resources. Since economic capital has been held constant here, a reasonable inference seems to be that parental monitoring of their children's out-of-school activities is more effective when both biological parents are present. Note that family structure has a statistically insignificant effect on pursuing PSE, suggesting that if a student has successfully completed high school, parental monitoring is no longer particularly necessary. The pattern of similarities and differences documented above lead to the conclusion that resilience considered collectively is of approximately equal importance for the educational pathways considered here. However, some aspects of resilience seem to protect more against dropping out, while others encourage participation in PSE. Hence the third hypothesis received only partial support.

The findings presented in this paper indicate that the concept of resilience can be fruitfully applied to youth's educational pathways, but with a number of important caveats. First, analyses of resilience need to be placed in the context of acceptance of cultural goals and the magnitude of possible barriers to achieving them. Aspirations represent a crucial ingredient in educational resilience: respondents with low reading achievement who nevertheless persist in their education hold high aspirations. At the same time, dropping out of high school does not represent a relinquishing of the cultural value of education, since the behaviour of dropouts is inconsistent with their aspirations; they desire significantly more education than they currently have-a finding consistent with other research (Tanner 1990). Likewise, barriers of all types had negative effects; these need to be held constant in any assessment of the role of resilience.

Second, several potential measures of resilience failed to have significant positive effects on educational pathways. Especially surprising is that neither perseverance in the face of academic difficulties, nor personal initiative in career information seeking activities had the expected effects. This is one indication that the concept of resilience may have limited value as a theoretical concept, since both of these factors are arguably central to what is ordinarily thought of as resilient behaviour. 
Third, even with the modifications proposed here, resilience cannot account for some of the findings. For example, immigrant youth might be thought of as facing additional barriers, since they have to adjust to both the Canadian culture and the Canadian school system. From this vantage point it is therefore interesting to see that their odds of pursuing PSE are 33 percent higher than that of their Canadian-born counterparts. Similarly anomalous from a resilience standpoint is the finding that visible minorities are more likely to pursue PSE, and vice versa, less likely to drop out of high school than their white counterparts. These findings are testimony to the fact that certain types of potential disadvantages can not only be overcome, but actually produce educational outcomes superior to those not facing such potential barriers-possibilities that are not easily incorporated into a resilience framework.

Finally, taking all the findings together, a reasonable conclusion is that the enabling mechanisms and social and institutional supports that facilitated the educational pathways of low achievers are rather similar to those found to be related to educational achievement of students generally. There is little evidence that educational resilience played any special role for students facing the obstacle of low reading achievement. For this reason it might be better to consider educational resilience to be a sensitizing rather than a theoretical concept. That is, it is primarily a heuristic device that helps one to seek for additional forms of enabling mechanisms and social supports, and organize or interpret the findings around such a theme. That is the approach used in this paper. As Crosnoe, Kirkpatrick Johnson, and Elder (2002:701) admonish, "more attention needs to be paid to the success stories - those adolescents who succeed" despite various barriers.

It is worth pondering about the fact that over two thirds of the low reading achievers analyzed in this paper managed to complete high school, and over one third participated in PSE. Some might argue that this is testimony to high levels of resilience in today's high school students. As corroborating evidence they might point to their remarkable achievement of obtaining a GPA of over 70 percent. Others might attribute these solid outcomes to a high school system that has somehow more effectively addressed the needs of low literacy students. As evidence for this interpretation they might cite the reduction of the high school dropout rate from 18 percent to 12 percent between the beginning and 
the end of the 1990s (Bowlby and McMullen 2002:26). There is, however, a third possibility. Merton's strain theory alerts us to unintended consequences whenever there is a strong consensus on cultural goals, but structured inequality in the means for achieving these goals. Under these circumstances, institutionally permitted (but not necessarily institutionally desired) mechanisms may be harnessed to achieve these ends. One set of institutionally permitted mechanisms is for parents and students to pressure teachers for higher marks. The resulting grade inflation has the consequence of making the institutionally-regulated means, namely high marks, accessible to a higher proportion of students. The data at hand cannot decide between these three possible interpretations. All that can be said is that Merton's means-end typology would predict grade inflation as one of the unintended consequences. 
Victor Thiessen

\section{References}

Aschaffenburg, Karen, and Ineke Maas. 1997. "Cultural and educational careers: The dynamics of social reproduction." American Sociological Review 62:573-587.

Attewell, Paul, and Juan Battle. 1999. "Home computers and school performance." The Information Society 15:1-10.

Benner, Aprile D., and Rashmita S. Mistry. 2007. "Congruence of mother and teacher educational expectations and low-income youth's academic competence." Journal of Educational Psychology 99:140-153.

Bouchey, Heather A., and Susan Harter. 2005. "Reflected appraisals, academic selfperceptions, and math/science performance during early adolescence." Journal of Educational Psychology 97:673-686.

Bourdieu, Pierre. 1977. "Cultural reproduction and social reproduction." in Power and Ideology in Education, edited by J. Karabel and A.H. Halsey. Oxford: Oxford University Press.

- 1986. "The forms of capital." Pp. 241-258 in Handbook of Theory and Research in the Sociology of Education, edited by James C. Richardson. New York: Greenwood.

—. 1990. In Other Words: Essays Towards a Reflexive Sociology. Stanford, California: Stanford University.

Bourdieu, Pierre, and Luc Boltanski. 1978. "Changes in social structure and changes in the demand for education." Pp. 197-227 in Contemporary Europe: Social Structure and Cultural Patterns, edited by Salvadore Giner and Margaret S. Archer. London: Routledge \& Kegan Paul.

Bowlby, Jeffrey W., and Kathryn McMullen. 2002. "At a Crossroads: First Results for the 18 to 20-Year-old Cohort of the Youth in Transition Survey." Ottawa: Human Resources Development Canada, Statistics Canada.

Butlin, George. 1999. "Determinants of postsecondary participation." Education Quarterly Review 5:9-35.

—. 2000. "Determinants of university and college leaving." Education Quarterly Review 6:8-23.

Cheung, Sin Yi, and Robert Andersen. 2003. "Time to read: Family resources and educational outcomes in Britain." Journal of Comparative Family Studies 34:413433.

Coleman, James S. 1988. "Social capital in the creation of human capital." American Journal of Sociology 94:S95-S120.

Crosnoe, Robert, Monica Kirkpatrick Johnson, and Glen H Elder, Jr. 2004. "Intergenerational Bonding in School: The Behavioral and Contextual Correlates of Student-Teacher Relationships." Sociology of Education 77:60-81.

Crosnoe, Robert, Rashmita S. Mistry, and Glen H. Elder, Jr. 2002. "Economic disadvantage, family dynamics, and adolescent enrollment in higher education." 
Journal of Marriage and the Family 64:690-702.

Crowder, Kyle, and Jay Teachman. 2004. "Do residential conditions explain the relationship between living arrangements and adolescent behavior?" Journal of Marriage and Family 66:721-738.

Dinovitzer, Ronit, John Hagan, and Patricia Parker. 2003. "Choice and circumstance: Social capital and planful competence in the attainments of immigrant youth." Canadian Journal of Sociology 28:463-488.

DiRago, Ana C., and George E. Vaillant. 2007. "Resilience in inner city youth: Childhood predictors of occupational status across the lifespan." Journal of Youth and Adolescence 36:61-70.

Eccles, Jacquelinne S., and Bonnie L. Barber. 1999. "Student council, volunteering, basketball, or marching band: What kind of extracurricular involvement matters?" Journal of Adolescent Research 14:10-43.

Eccles, Jacquelynne S., Mina N. Vida, and Bonnie Barber. 2004. "The relation of early adolescents' college plans and both academic ability and task-value beliefs to subsequent college enrollment." Journal of Early Adolescence 24:63-77.

Entwisle, Doris R, Karl L Alexander, and Linda S. Olson. 2004. "Temporary as compared to permanent high school dropout." Social Forces 82:1181-1205.

Evans, M. D. R., Jonathan Kelley, and Richard A. Wanner. 2001. "Educational attainment of the children of divorce: Australia, 1940-90." Journal of Sociology 37:275-297.

Fan, Xitao, and Michael Chen. 2001. "Parental involvement and students' academic achievement: A meta-analysis." Educational Psychology Review 13:1-22.

French, Doran C., and Jody Conrad. 2001. "School dropout as predicted by peer rejection and antisocial behavior." Journal of Research on Adolescence 11:225-244.

Gilbert, Sid, Lynn Barr, Warren Clark, Matthew Blue, and Deborah Sunter. 1993. "Leaving School: Results from a National Survey Comparing School Leavers and High School Graduates 18 to 20 Years of Age." Statistics Canada.

Glick, Jennifer E., and Michael J. White. 2004. "Post-secondary school participation of immigrant and native youth: The role of familial resources and educational expectations." Social Science Research 33:272-299.

Hagan, John, Ross MacMillan, and Blair Wheaton. 1996. "New kid in town: Social capital and the life course effects of family migration on children." American Sociological Review 61:368-385.

Human Resources Development Canada, Canada Council of Ministers of Education, and Statistics Canada. 2001. Measuring Up: The Performance of Canada's Youth in Reading, Mathematics and Science. OECD PISA Study--First Results for Canadians Aged 15. Ottawa.

Hymel, Shelley, and Laurie Ford. 2003. "School completion and academic success: The impact of early social-emotional competence." Pp. 1-7 in Encyclopedia on Early Childhood Development [online], edited by Richard E Tremblay, RG Barr, and 
RDeV Peters. Montreal, Quebec: Centre of Excellence for Early Childhood Development. Available at: http://www.excellenceearlychildhood.ca/documents/Hymel-FordANGxp.pdf. Accessed August 20, 2005.

Jordan, Will J., and Saundra M. Nettles. 2000. "How students invest their time outside of school: Effects on school-related outcomes." Social Psychology of Education $3: 217-243$.

Krahn, Harvey, and Julie Hudson. 2006. "Pathways of Alberta Youth Through the PostSecondary System into the Labour Market, 1996-2003." Ottawa: Canadian Policy Research Networks.

Lambert, Mylène, Klarka Zeman, Mary Allen, and Patrick Bussière. 2004. "Who Pursues Postsecondary Education, Who Leaves and Why: Results from the Youth in Transition Survey." Ottawa: Statistics Canada and Human Resources and Skills Development Canada.

Looker, E. Dianne. 1994. "Active capital: the impact of parents on youths' educational performance and plans." Pp. 164-187 in Sociology of Education in Canada, edited by Lorna Erwin and David MacLennan. Toronto: Copp Clark Longman.

Luthar, Suniya S., Dante Cicchetti, and Bronwyn Becker. 2000. "The construct of resilience: A critical evaluation and guidelines for future work." Child Development 71:543-562.

Mahoney, Joseph L. 2000. "School extracurricular activity participation as a moderator in the development of antisocial patterns." Child Development 71:502-516.

Meltzer, Lynn, Tamar Katzir, Lynne Miller, Ranjini Reddy, and Bethany Roditi. 2004. "Academic self-perceptions, effort, and strategy use in students with learning disabilities: Changes over time." Learning Disabilities Research \& Practice 19:99108.

Merton, Robert. K. 1938. "Social structure and anomie." American Sociologial Review 3:672-682.

Musick, Kelly, and Larry Bumpass. 1999. "How do prior experiences in the family affect transitions to adulthood?" Pp. 69-102 in Transitions to Adulthood in a Changing Economy: No Work, No Family, No Future?, edited by Alan Booth, Ann C. Crouter, and Michael J. Shanahan. Westport, Connecticut: Praeger.

Pong, Suet-Ling, and Dong-Beom Ju. 2000. "The effects of change in family structure and income on dropping out of middle and high school." Journal of Family Issues 21:147-169.

Pribesh, Shana, and Douglas B. Downey. 1999. "Why are residential and school moves associated with poor school performance?" Demography 36:521-534.

Reynolds, Arthur J., Suh-Ruu Ou, and James W. Topitzes. 2004. "Paths of effects of early childhood intervention on educational attainment and delinquency: A confirmatory analysis of the Chicago child-parent centers." Child Development $75: 1299-1328$.

Roosa, Mark W. 2000. "Some thoughts about resilience versus positive development, 
main effects versus interactions, and the value of resilience." Child Development 71:567-569.

Schoon, Ingrid, Samantha Parsons, and Amanda Sacker. 2004. "Socioeconomic adversity, educational resilience, and subsequent levels of adult adaptation." Journal of Adolescent Research 19:383-404.

Scott, Jacqueline. 2004. "Family, gender, and educational attainment in Britain: A longitudinal study." Journal of Comparative Family Studies 35:565-589.

Statistics Canada. 2006 Youth in Transition Survey (YITS) Cohort A-19-year-olds Cycle 3 User Guide

Stearns, Elizabeth, Stephanie Moller, and Judith R. Blau. 2004. "Retention and school dropout: Examining connectivity between children and schools." San Francisco: Paper presented at the annual meetings of the American Sociological Association.

Stoner-Eby, Scott. 2002. "Three Essays on Adolescent Behavior in an Urban High School Context: Black-White Differences in School Experiences and Smoking; A Multifacted Approach to School Engagement and Dropout; Black-White Differences in Evidence of Opposition to School." in Sociology. Philadelphia: University of Pennsylvania.

Sussman, Steve, Louise A. Rohrbach, Silvana Skara, and Clyde W Dent. 2004. "Prospective prediction of alternative high school graduation status at emerging adulthood." Journal of Applied Social Psychology 34:2452-2468.

Tanner, Julian. 1990. "Reluctant rebels: A case study of Edmonton high school dropouts." Canadian Review of Sociology and Anthropology 27:74-94.

Teachman, Jay D., Kathleen Paasch, and Karen Carver. 1997. "Social capital and the generation of human capital." Social Forces 75:1343-59.

Thiessen, Victor. 2007. "Academic performance, human capital skill formation, and postsecondary education: A comparison of First Nation, immigrant, visible minority, and other native-born Canadian youth." in Working paper Number 1. Vancouver, BC: Canadian Labour and Skills Researcher Network, Working Paper Number 1 (http://www.econ.ubc.ca/clsrn/publications/workingpapers/Thiessen_workshop_c over\%20page.pdf).

Tinklin, Teresa, and Linda Croxford. 2000. "High-attaining female school leavers." Edinburgh: Scottish Executive.

Tomkowicz, Joanna, and Tracey Bushnik. 2003. "Who goes to post-secondary education and when: Pathways chosen by 20 year-olds." Ottawa: Statistics Canada.

Videon, Tami M. 2002. "Who plays and who benefits: Gender, interscholastic athletics, and academic outcomes." Sociological Perspectives 45:415-444.

Wasonga, Teresa. 2002. "Gender effects on perceptions of external assets, development of resilience and academic achievement: Perpetuation theory approach." Gender Issues 20:43-54.

Wayman, Jeffrey C. 2002. "The utility of educational resilience for studying degree attainment in school dropouts." Journal of Educational Research 95:167-178. 
Victor Thiessen

Wood, Dana, Rachel Kaplan, and Vonnie C. McLoyd. 2007. "Gender differences in the educational expectations of urban, low-income African American youth: The role of parents and the school." Journal of Youth and Adolescence 36:417-427.

Zaff, Jonathan F., Kristin A. Moore, Angela Romano Papillo, and Stephanie Williams. 2003. "Implications of extracurricular activity participation during adolescence on positive outcomes." Journal of Adolescent Research 18:599-630. 